\title{
Characterisation of episodic aerosol types over the Australian continent
}

\author{
Y. Qin and R. M. Mitchell \\ CSIRO Marine and Atmospheric Research, Centre for Australian Weather and Climate Research, a partnership between \\ CSIRO and the Australian Bureau of Meteorology, Canberra, ACT, Australia
}

Received: 1 July 2008 - Published in Atmos. Chem. Phys. Discuss.: 3 November 2008

Revised: 2 March 2009 - Accepted: 6 March 2009 - Published: 19 March 2009

\begin{abstract}
Classification of Australian continental aerosol types resulting from episodes of enhanced source activity, such as smoke plumes and dust outbreaks, is carried out via cluster analysis of optical properties obtained from inversion of sky radiance distributions at Australian aerosol ground stations using data obtained over the last decade. The cluster analysis distinguishes four significant classes, which are identified on the basis of their optical properties and provenance as determined by satellite imagery and backtrajectory analysis. The four classes are identified respectively as aged smoke, fresh smoke, coarse dust and a superabsorptive aerosol. While the first three classes show similarities with comparable aerosol types identified elsewhere, the super-absorptive aerosol has no obvious foreign prototype. The class identified as coarse dust shows a prominent depression in single scattering albedo in the blue spectral region due to absorption by hematite, which is shown to be more abundant in central Australian dust relative to the "dust belt"of the Northern Hemisphere. The super-absorptive class is distinctive in view of its very low single scattering albedo $(\sim 0.7$ at $500 \mathrm{~nm}$ ) and variable enhanced absorption at $440 \mathrm{~nm}$. The strong absorption by this aerosol requires a high black carbon content while the enhanced blue-band absorption may derive from organic compounds emitted during the burning of specific vegetation types. This aerosol exerts a positive radiative forcing at the top of atmosphere (TOA), with a large deposition of energy in the atmosphere per unit aerosol optical depth. This contrasts to the other three classes where the TOA forcing is negative. Optical properties of the four types will be used to improve the representation of Australian con-
\end{abstract}

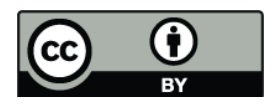

Correspondence to: R. M. Mitchell (ross.mitchell@csiro.au) tinental aerosol in climate models, and to enhance the accuracy of satellite-based aerosol retrievals over Australia.

\section{Introduction}

Airborne particulates or aerosols play a significant role in climate both through direct interaction with atmospheric radiation, and indirectly by modifying cloud optical properties and persistence. A comprehensive summary of the current level of understanding of climate-related aerosol is given in chapter 2 of the IPCC fourth assessment report (Forster et al., 2007). Despite significant advances over recent years, the level of scientific understanding is still rated as "mediumlow" for direct aerosol radiative forcing, and "low" for the combined indirect effects. Much of this uncertainty derives from the geographical and temporal inhomogeneity in aerosol optical properties and loadings, even though substantial progress has been made over recent years through a variety of complementary techniques. These range from in-situ sampling, through ground-based remote sensing networks, to the retrieval of aerosol properties from satellite data. In the present context, Dubovik et al. (2002) demonstrated the potential of optical properties retrieved from AERONET skyradiance inversions to identify globally significant aerosol types.

Further progress in this area has been made through the intercomparison of global aerosol models and the synthesis of the models with observational datasets as undertaken in the AeroCom project (Kinne et al., 2006). These studies suggest that the nominal aerosol optical depth over Australia is small in comparison to major source regions, with modest negative shortwave radiative forcing at the top of atmosphere (TOA) leading to a net cooling. However, the same study predicts globally significant deposition of energy within the

Published by Copernicus Publications on behalf of the European Geosciences Union. 
atmosphere over the Australian region $\left(1 \sim 2 \mathrm{~W} \mathrm{~m}^{-2}\right)$, in part due to aerosol absorption. As pointed out by Forster et al. (2007), tropospheric heating due to this forcing is expected to impact on regional climate through altered convective circulation. In addition, many of these results are based on largely untested assumptions about the similarity between the optical properties of Australian and foreign aerosol types.

The role of aerosol in Australian climate was recently reviewed by Rotstayn et al. (2009a). Among a number of priority areas, they identified a need for improved characterisation of biomass burning aerosol from Australia and Indonesia, and better understanding of the Australian dust source. A study of the radiative impact of aerosol from biomass burning in Northern Australia by O'Brien and Mitchell (2003) suggested large tropospheric heating, while Luhar et al. (2008) found mean TOA radiative forcing of $-4 \mathrm{~W} \mathrm{~m}^{-2}$ across the Northern Territory during the 2004 burning season, with a markedly asymmetric geographic distribution of the forcing. Characterisation of the optical properties of Australian biomass burning aerosol is restricted to a few case studies. For example, Gras et al. (1999) and Carr et al. (2005) conducted airborne measurements of tropical biomass burning aerosol, while Mitchell et al. (2006) determined the optical properties of the smoke plume over Canberra in January 2003 using inversions of sky-radiance distributions from a ground-based sun photometer. Earlier characterisation of smoke aerosol from temperate forest fires was undertaken by Vines et al. (1971) and Evans et al. (1976).

Australia is the dominant dust source in the Southern Hemisphere (Tanaka and Chiba, 2006), with a range of environmental impacts including iron fertilization of surrounding oceans and possible climate feedbacks (Cassar et al., 2007). However, a systematic characterisation of the composition and optical properties of Australian dust aerosol is currently lacking.

Over the last decade, aerosol characterisation on the Australian continent has been advanced by deployment of sunphotometer networks by CSIRO and the Bureau of Meteorology (BoM). The networks are complementary with BoM instruments located at meteorological observing stations with an emphasis on radiation budget, while the CSIRO Aerosol Ground Station Network (AGSNet) focuses on remote locations targeting particular aerosol types, specifically biomass burning aerosol in the tropical north, and aeolian dust in the arid zone. Performance of the instruments deployed in the two networks was compared by Mitchell and Forgan (2003). The AGSNet stations are federated with the Aerosol Robotic Network (AERONET) operated by NASA (Holben et al., 1998) ensuring standardized calibration and global dissemination of data.

In this study, optical properties obtained from the inversion of sky-radiance distributions measured at AGSNet sites are analysed using a clustering method to determine statistically significant groupings, and hence to infer the characteristics of dominant aerosol types on the Australian continent. As fur-

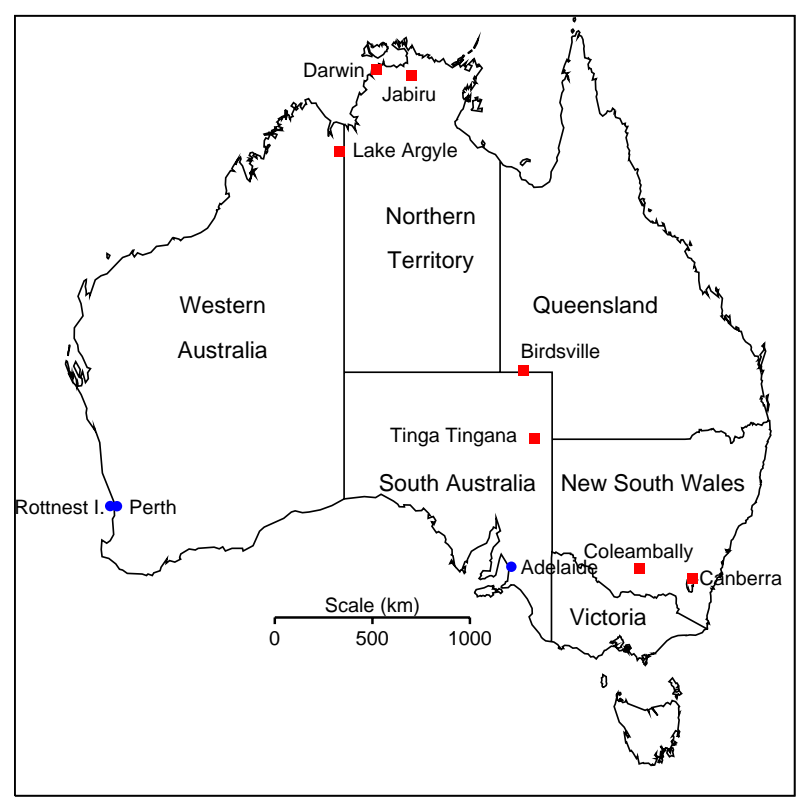

Fig. 1. Location of the observation sites used in this analysis. CSIRO Aerosol Ground Station Network (AGSNet) sites are shown as red squares, and other sites as blue dots. All stations are affiliated with AERONET.

ther discussed below, attention is restricted to aerosol events or episodes where the aerosol optical depth is significantly elevated over background levels. A comparable method was applied globally by Omar et al. (2005) who derived statistically significant groupings in aerosol optical properties as a basis for satellite inversion algorithms. Levy et al. (2007) applied a similar method to determine improved base aerosol models for enhanced MODIS aerosol products. However, neither study yielded any information regarding the characteristics of Australian aerosol.

\section{Data selection}

The location of the Australian AERONET sites is shown in Fig. 1. These are all CSIRO/AGSNet sites with the exception of Adelaide, Perth and Rottnest Island, which are operated independently. The sites at Darwin, Jabiru and Lake Argyle target smoke aerosol from tropical savanna biomass burning, while the arid zone sites at Tinga Tingana and Birdsville are located near major dust source regions in the Lake Eyre basin. The AGSNet station at Colleambally was operated in the period 2001-2003 in conjunction with crop remote sensing activities.

All available data at these sites, aerosol optical depth, single scattering albedo, phase function, asymmetry parameter and a large number of other optical and microphysical variables, were downloaded from the AERONET website. These parameters were derived from the direct solar radiance 
and scattered sky radiance measured by Cimel sunphotometers and inverted using the standard AERONET processing (Dubovik and King, 2000; Dubovik et al., 2000, 2002, 2006).

AERONET version 2 level 1.5 inversion data were used in the analysis. The stringent filtering criterion applied at level 2.0 removes all data where the extinction optical depth at $440 \mathrm{~nm}\left(\tau_{440}\right)$ is below 0.4. For the current data set, this eliminates most of the data records available, leaving only a small sample of 1079 records. Instead, level 1.5 was used with a less strict criterion of $\tau_{440}>0.2$. This choice increases the sample size to 4559 records, allowing better statistics in the classification, at the cost of increased uncertainty in the derived optical properties. The increased uncertainty is illustrated by calculating the relative uncertainty in single scattering albedo, based on the analysis of Dubovik et al. (2000), Eq. (10). This uncertainty is the sum of two components, the first linearly related to the relative uncertainty in measured sky radiance, while the second is the relative uncertainty in extinction aerosol optical depth. Comparison of calibration differences between CSIRO and NASA Goddard Space Flight Center over several years suggests relative uncertainty in sky radiance of $\sim 3 \%$ (Mitchell and Campbell, 2004), while Mitchell and Forgan (2003) found standard uncertainties in the measurement of extinction aerosol optical depth of typically 0.0035 under Australian outback conditions. We note that these uncertainties are smaller than those assumed for the network-wide analysis of Dubovik et al. (2000). For $\tau_{440}=0.4$, the resulting standard uncertainty in single scattering albedo ranges from $6 \%$ at $440 \mathrm{~nm}$ to $5 \%$ at the longer wavelengths, while for $\tau_{440}=0.2$ the corresponding uncertainties are $9 \%$ at $440 \mathrm{~nm}$ and $7 \%$ at the longer wavelengths. This increase in uncertainty of $2-3 \%$ suggests only a modest increase in the noise associated with the retrieved optical properties used in the present analysis, as compared with level 2 data. Further uncertainty analysis is considered below.

Of the 4559 records used in the classification analysis, only 25 come from the non-AGSNet sites. Because of this small number of records, these sites will not be separately referenced when reporting the classification results.

\section{Clustering classification}

The analysis consists of two stages. In the first stage, noisy background points were removed using a Locally Scaled Density Based Clustering (LSDBC) algorithm (Bicici and Yuret, 2007; Sander et al., 1998). This algorithm is able to cluster "density-connected" points while leaving scattered outliers unclassified. The outliers were subsequently removed from the dataset together with clusters of less than 100 points. In total, 286 records where removed in this stage.

In the second stage, the noise-cleared dataset was classified using an agglomerative complete-link clustering algorithm of the hierarchical category (Kotsiantis and Pintelas,
2004; Grira et al., 2005), as implemented in IDL (Interactive Data Language). In this work, the so called City-block or Manhattan distance between any two points was used, defined as $\sum_{i=1}^{n}\left|a_{i}-b_{i}\right|$ where $a$ and $b$ denote two records with $n$ parameters each.

A brief description of the algorithm is as follows. Initially, each single record is treated as a class. The distances between each pair of classes are calculated. The distance between two classes, A and B, is defined to be the maximum distance between any one of class A records and any one of class B records (the so called complete-link). The two closest classes are then merged as one class. The last two steps are repeated until the minimum distance among the paired classes reaches a prescribed criterion. This criterion is experimental and controls the number of classes.

The following twelve parameters comprising optical properties computed from the retrieved microphysical parameters, are used in the cluster analysis:

- single scattering albedo $(\varpi)$ at $440,670,870$ and $1020 \mathrm{~nm}$;

- the ratio $R_{s s a}=\varpi_{870} / \varpi_{440}$;

- Aerosol optical depth at 670, 870 and $1020 \mathrm{~nm}$, normalized by the value at $440 \mathrm{~nm}$;

- Asymmetry parameter at all four bands.

These parameters were chosen because they best combine a close relation to the measured radiance field, with direct relevance to aerosol radiative forcing and satellite aerosol retrieval. Following preliminary analysis, the single scattering albedo ratio was included to discriminate between aerosol types with different degrees of absorption in the blue spectral region. Before the cluster analysis, each of the four groups of parameters was normalized by scaling the minimum of the group to 0.0 and the maximum to 1.0. This step ensures that the relative contribution of the parameters to the distance calculation is balanced.

After the records are classified, the centers of the classes are calculated as the density weighted average for each parameter and each class. The density at point $p$ is calculated as (Bocici and Yuret, 2007):

$\rho_{k}(p)=\frac{k}{\epsilon_{k}^{n}(p)}$

where $\epsilon_{k}(p)$ is the distance between point $p$ and its $k$ th nearest neighbour, $n$ is the number of parameters involved in the classification, and $k$ is a parameter experimentally decided in the first stage by the LSDBC algorithm.

\section{Classification results and interpretation}

By applying the clustering analysis, the 4273 records were classified into five classes, labelled as classes 0 to 4 in the 
Table 1. The distance between the centers of paired classes (nondiagonal elements) and the density weighted average distance of class members to their respective class centers (diagonal elements). Distances are calculated using the scaled parameters. See Sect. 3 for parameter scaling and distance definition.

\begin{tabular}{ccccc}
\hline Class & 0 & 1 & 2 & 3 \\
\hline 0 & $\mathbf{0 . 4 3}$ & 0.78 & 3.41 & 2.07 \\
1 & 0.78 & $\mathbf{0 . 4 1}$ & 4.19 & 2.32 \\
2 & 3.41 & 4.19 & $\mathbf{0 . 4 5}$ & 5.06 \\
3 & 2.07 & 2.32 & 5.06 & $\mathbf{0 . 5 6}$ \\
\hline
\end{tabular}

Table 2. The number of records in each class at each site. The values in the parentheses are the percentage of records in each class relative to the total number of records at the site. The totals listed in the right-hand column include discarded records.

\begin{tabular}{lccccc}
\hline Class & 0 & 1 & 2 & 3 & Total \\
Site & & & & & \\
\hline Darwin & 386 & 204 & 12 & 16 & 635 \\
& $(61 \%)$ & $(32 \%)$ & $(2 \%)$ & $(3 \%)$ & \\
Jabiru & 911 & 481 & 71 & 106 & 1619 \\
& $(56 \%)$ & $(30 \%)$ & $(4 \%)$ & $(7 \%)$ & \\
Lake & 578 & 688 & 118 & 68 & 1504 \\
Argyle & $(38 \%)$ & $(46 \%)$ & $(8 \%)$ & $(5 \%)$ & \\
Tinga & 141 & 42 & 144 & 39 & 375 \\
Tingana & $(38 \%)$ & $(11 \%)$ & $(38 \%)$ & $(10 \%)$ & \\
Birdsville & 5 & 10 & 30 & 0 & 45 \\
& $(11 \%)$ & $(22 \%)$ & $(67 \%)$ & $(0 \%)$ & \\
Canberra & 51 & 29 & 0 & 1 & 81 \\
& $(63 \%)$ & $(36 \%)$ & $(0 \%)$ & $(1 \%)$ & \\
\hline Total & 2078 & 1460 & 377 & 230 & 4273 \\
& $(49 \%)$ & $(34 \%)$ & $(9 \%)$ & $(5 \%)$ & \\
\hline
\end{tabular}

order of the number of records in each class. Class 4 , which contains 128 or $3 \%$ of the total records, appears fragmented, with no significantly large block of records lasting two or more consecutive days at any given site. This may be due to inversion error or due to short-lived variations of the aerosol properties. In view of the uncertain nature and the difficulty of identifying sources for such scattered records, this class was discarded.

Table 1 lists the distance between pairs of the remaining four classes and the averaged distance of class members to their respective class centers. The table shows that, with the exception of classes 0 and 1, the classes are in general well separated from each other. It will be shown later in this section that classes 0 and 1 are sub-classes of a larger group with related size distributions and optical properties.

Table 2 lists the number of records assigned to the different classes at each site, and the percentage of each class relative to the total number of records. Figure 2 shows the annual

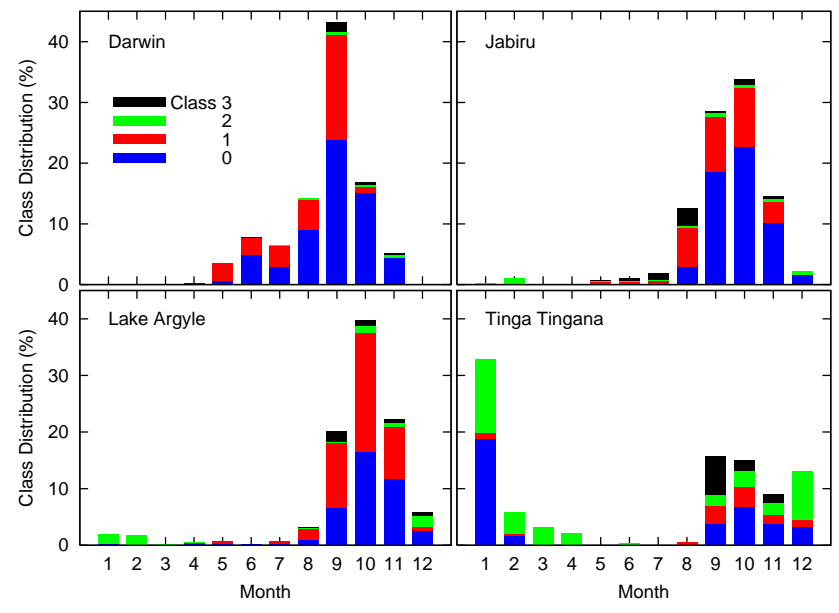

Fig. 2. Seasonal distribution of aerosol classes at the four primary stations.

distribution of the classes at each site, as a percentage of the number of records in a given month for each class relative to the total number of records at that site.

Table 3 lists selected aerosol properties at the four class centers, and their spatial variability. The parameters were chosen to illustrate a range of optical and microphysical characteristics, and not all were used in the clustering analysis. The Ångström exponent follows from

$\tau_{\lambda} \propto \lambda^{-\alpha}$

with $\alpha$ defined between the wavelengths ( $\lambda$ ) 440 and $870 \mathrm{~nm}$; it encapsulates the spectral dependence of aerosol optical depth in a single parameter. The parameter $f_{v}$ is the volume fraction of the fine mode as determined from the bimodal size distribution in the AERONET inversion. The spatial variability, shown in parentheses beneath each parameter, is defined as the standard deviation of parameter $p$ over all $N$ sites,

$\sigma(p)=\sum_{i=1}^{N} \sqrt{\frac{\left(\bar{p}_{i}-\bar{p}\right)^{2}}{N-1}}$,

where $\bar{p}_{i}$ denotes the class center for site $i$, and $\bar{p}$ is the class center over all sites. It can be seen that the class center parameters are generally stable across the sites, although with elevated variability in coarse dust aerosol optical depth, and fine mode fraction for the aged smoke and super-absorptive classes. This generally small spatial variability suggests that a single set of optical and microphysical properties may be used continent-wide. Note that the reported aerosol optical depths are biased by the selection criterion of $\tau_{440}>0.2$ for inclusion in the clustering analysis, and so represent episodic events that passed AERONET inversion screening criteria.

Figure 3 displays the size distribution and spectral variation of single scattering albedo, normalized extinction optical depth, and the asymmetry parameter at the density-weighted 
Table 3. Characteristic parameters at the center of the classes, their spatial variability defined as the standard deviation across the sites (in parentheses), and their identification. Parameters shown are the aerosol optical depth at $440 \mathrm{~nm}, \tau_{440}$, Ångström exponent $\alpha_{440-870}$, single scattering albedo at $440 \mathrm{~nm}, \varpi_{440}$, single scattering albedo ratio $R_{s s a}=\varpi_{870} / \varpi_{440}$, asymmetry parameter at $440 \mathrm{~nm}, g_{440}$, and the fraction of fine mode volume to the total volume, $f_{v}$.

\begin{tabular}{cccccccl}
\hline Class & $\tau_{440}$ & $\alpha_{440-870}$ & $\varpi_{440}$ & $R_{s s a}$ & $g_{440}$ & $f_{v}$ & Identification \\
\hline 0 & 0.31 & 1.34 & 0.89 & 0.96 & 0.66 & 0.38 & Smoke (aged) \\
& $(0.02)$ & $(0.02)$ & $(0.01)$ & $(0.01)$ & $(0.01)$ & $(0.07)$ & \\
1 & 0.39 & 1.61 & 0.87 & 0.94 & 0.65 & 0.51 & Smoke (fresh) \\
& $(0.11)$ & $(0.05)$ & $(0.01)$ & $(0.01)$ & $(0.01)$ & $(0.04)$ & \\
2 & 0.29 & 0.04 & 0.94 & 1.04 & 0.74 & 0.03 & Coarse dust \\
& $(0.24)$ & $(0.16)$ & $(0.04)$ & $(0.04)$ & $(0.02)$ & $(0.02)$ & \\
3 & 0.28 & 1.21 & 0.72 & 0.84 & 0.67 & 0.33 & Super-absorptive \\
& $(0.03)$ & $(0.20)$ & $(0.02)$ & $(0.01)$ & $(0.01)$ & $(0.09)$ & \\
\hline
\end{tabular}

class centers. To estimate the impact of uncertainties in the optical parameters on this classification, we carried out an evaluation of its robustness following Omar et al. (2005). Specifically, $10 \%$ normally distributed random errors were introduced into the size distribution and complex refractive index of each record, following which the optical parameters were recalculated using Mie code. These newly obtained records were then classified identically to the unperturbed data. This process was carried out 12 times, leading to 13 sets of class centers including the unperturbed case. The standard deviations of the optical parameters at the class centers were then calculated, and shown as the vertical bars in Fig. 3. The classification result is seen to be robust with stable class centers despite the noise added to the data. However there is some blurring of classes as seen, for example, in the overlap between classes 0 and 1 in single scattering albedo, and between classes 0 and 3 in normalized extinction and asymmetry parameter. These effects will be considered along with a more general discussion of the four classes in subsequent sections.

\subsection{Classes 0 and 1}

Class 0 and class 1 are the most common of all, with $83 \%$ of all the records being classified in these classes. The particles are small and moderately absorbing, with $\varpi_{440}$ being 0.89 and 0.87 , respectively. They are the dominant aerosols at the three tropical sites (93\% of the total records are classes 0 or 1 at Darwin, $86 \%$ at Jabiru and $84 \%$ at Lake Argyle). For these tropical sites, Fig. 2 shows a clear annual pattern of occurrence of the two classes with the peak in SeptemberOctober.

Considering the temporal and spatial occurrence and the optical properties of classes 0 and 1 , it can be confidently asserted that these aerosols arise from biomass burning. This is supported by MODIS images together with air mass backtrajectory analysis computed using HYSPLIT (Draxler and Hess, 1997). For example, the classified records at Darwin show a continuous period of class 0 or 1 from 3 to 11
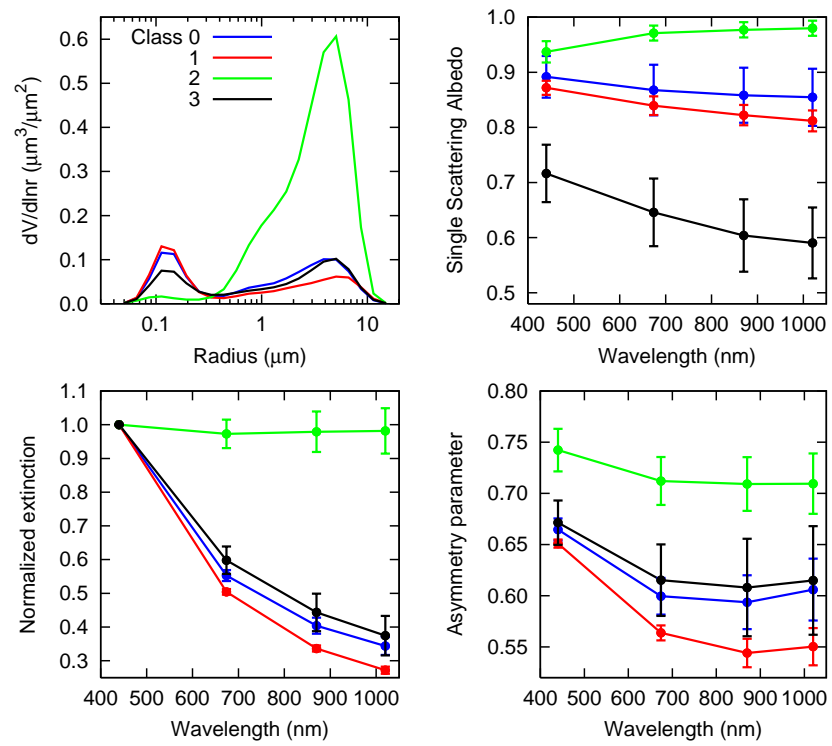

Fig. 3. Size distribution and selected optical properties of the four aerosol classes at the density-weighted class centers. The vertical bars represent the standard deviation among 13 clustering analyses, one of which corresponds to the class center, and a further twelve where $10 \%$ gaussian noise was added to the complex refractive index and size distribution.

September 2004. On MODIS images for the same period, either visible smoke plumes can be seen clearly over Darwin, or back-trajectories show that smoke has been transported from sources elsewhere. Biomass burning in the tropical savanna during the dry season from May to September is a well-studied phenomenon with major contributions to Australia's greenhouse gas and particulate emissions (Meyer et al., 2008).

Figure 3 shows that class 0 has a reduced fine mode and larger coarse mode relative to class 1 , and is less absorbing. This is consistent with the identification of classes 0 and 1 


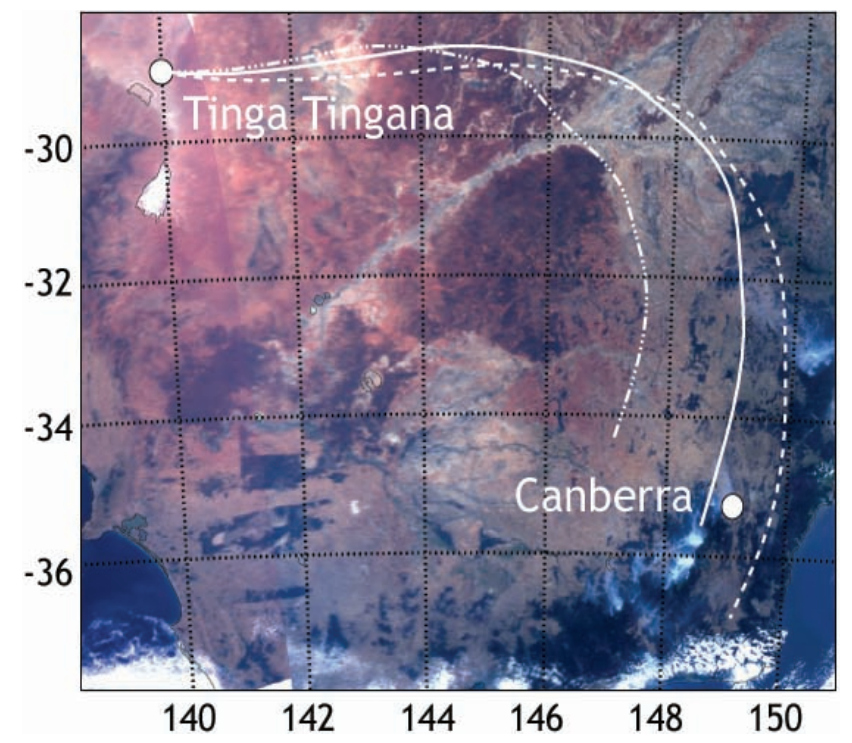

Fig. 4. Back-trajectory analysis showing the transport of smoke from the fires south of Canberra to Tinga Tingana in January 2003. The image was obtained from MODIS Terra on 9 January 03:35 UTC, while the trajectories run back $48 \mathrm{~h}$ from 11 January 04:00 UTC. The dashed, solid and dot-dashed line are for initial altitudes of $500 \mathrm{~m}, 1000 \mathrm{~m}$, and $1500 \mathrm{~m}$, respectively.

as aged and fresh smoke, respectively. As summarized by Forster et al. (2007), there is observational evidence that savanna smoke aerosol ages on a timescale of $\sim 5 \mathrm{~h}$ with increase in mid-visible SSA from 0.85 to 0.90 found by Abel et al. (2003) during the Southern African Regional Science Initiative (SAFARI) in August-September 2000. In the same campaign, Eck et al. (2003) found evidence for increases in particle size associated with increasing aerosol optical depth, although not uniformly across the study area. These changes in single scattering albedo and size distribution are consistent with the overlap between classes 0 and 1 mentioned above, and can be understood as the expected spread in microphysical properties as plumes age and migrate from class 1 to class 0 .

A surprising result of this analysis is the large number of records assigned to the "smoke" classes 0 and 1 at the arid zone stations that are distant from major biomass burning sources. For example, at Tinga Tingana, 38\% of records were assigned to class 0 and $11 \%$ to class 1 . Of all the class 0 records at Tinga Tingana, almost half occurred in January 2003, when extensive fires were burning in the forested regions of South-Eastern Australia, with devastating impact on urban Canberra and subsequent dense pall of smoke (Mitchell et al., 2006).

The air mass back-trajectories in Fig. 4 show how smoke generated from fires in the Brindabella and Namadgi National Parks west of Canberra was transported over $1500 \mathrm{~km}$ across New South Wales to Tinga Tingana in the North of

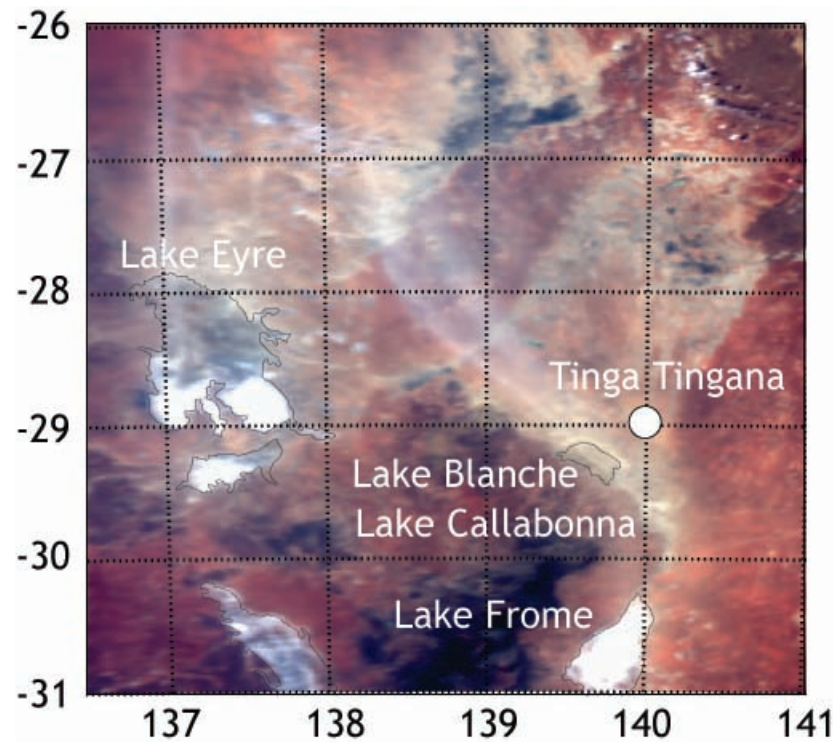

Fig. 5. Dust storm originating from Lakes Eyre, Blanche and Callabonna, coinciding with a class 2 episode at Tinga Tingana. The image was obtained from MODIS Aqua on 14 January 2003 at 03:50 UTC.

South Australia. The temporal variation of aerosol optical depth observed at Tinga Tingana over the period of 8-14 January 2003 is consistent both with air mass back-trajectories and the distribution and extent of smoke plumes identified from MODIS images.

\subsection{Class 2}

About $38 \%$ of the records at Tinga Tingana were classified as class 2, as were $67 \%$ at Birdsville, $8 \%$ at Lake Argyle and $4 \%$ at Jabiru. This class consists predominantly of coarse particles with $97 \%$ of the total volume in the coarse mode which has an effective radius of $2.2 \mu \mathrm{m}$. Considering the optical properties (Fig. 3), temporal distribution (Fig. 2) and site distributions (Table 2) it is evident that this class is dust aerosol.

This is supported by MODIS imagery, such as the image in Fig. 5 showing dust deflation from Lake Callabonna with a plume extending over Tinga Tingana.

Both Tinga Tingana and Birdsville are located near major dust sources: Tinga Tingana is sited $40 \mathrm{~km}$ north of Lake Blanche, one of a series of normally dry lakes that receive sediment from major waterways to the North during flood events every decade or so (Armstrong, 1990). Birdsville is surrounded by dust-producing regions, being located on the eastern fringe of the Simpson desert, lying to the North of the Strzelecki desert, and west of the Channel Country through which Queensland's inland-flowing rivers pass en route to Lake Eyre. The high incidence of dust activity in the region encompassing both sites is shown in the Dust Storm Index 
Table 4. Composition of Class 2 (coarse dust) aerosol obtained by fitting the spectral distribution of single scattering albedo at Tinga Tingana, Birdsville, Lake Argyle and Jabiru, with or without hematite included. The left portion of the table shows results assuming internal mixing of the minerals, while the rightmost column shows the hematite fraction assuming external mixing.

\begin{tabular}{lrcccccc}
\hline & \multicolumn{9}{c}{ Mixing: Internal } & External \\
\hline \multicolumn{1}{c}{ Site } & \multicolumn{3}{c}{$\begin{array}{c}\text { Volume } \\
(\%)\end{array}$} & \multicolumn{2}{c}{$\begin{array}{c}\text { Standard error } \\
\left(\times 10^{-3}\right)\end{array}$} & $\begin{array}{c}\text { Volume } \\
(\%)\end{array}$ \\
& $N_{\text {rec }}$ & Hematite & Quartz & Feldspar & W/Hem. & No Hem. & Hematite \\
\hline Tinga Tingana & 144 & 0.45 & 34.4 & 65.2 & 0.87 & 30.3 & 15.9 \\
Birdsville & 30 & 0.33 & 99.7 & 00.0 & 1.69 & 26.6 & 12.0 \\
Lake Argyle & 118 & 0.06 & 95.0 & 4.9 & 0.31 & 6.0 & 6.0 \\
Jabiru & 71 & 0.05 & 59.0 & 41.0 & 4.44 & 6.0 & 7.4 \\
\hline
\end{tabular}

(DSI) maps of McTainsh et al. (1998); see also Fig. 10 of Webb et al. (2006). The DSI maps also show moderate intermittent dust activities at Lake Argyle, which lies to the North of the Tanami desert, a significant dust source.

Class 2 aerosol exhibits a distinct feature in the spectral distribution of single scattering albedo, with a depression at $440 \mathrm{~nm}$ followed by a gradual increase at longer wavelengths, as shown in Fig. 3. As discussed below in Sect. 4.4, this feature is seen in desert dust from other regions (Dubovik et al., 2002; Koven and Fung, 2006; Levy et al., 2007) and is due to absorption in the blue spectral region by the iron oxide hematite.

Koven and Fung (2006) used the measured spectral shape to infer hematite content at a number of AERONET stations around the globe, although no Australian stations were included. They found that the required hematite content depends critically on its assumed mixing state, being at least an order of magnitude greater if the hematite is externally mixed rather than internally mixed. Here we develop a similar approach by reconstructing the spectral shape of the single scattering albedo using Mie theory. We first chose three components, quartz, feldspar and hematite, as the mineral constituents of the coarse dust. This choice was based on the global mineralogy of erodible fractions presented in Claquin et al. (1999). The coarse (silt) fraction $(2-50 \mu \mathrm{m})$ was used since, as shown in Table 3, 97\% by volume of class 2 aerosol comes from the coarse mode. Gypsum, another coarse component appearing in the Claquin et al. map, was ignored as it accounts for only $\sim 2 \%$ of the total coarse fraction.

For the case of internal mixing, the effective refractive index of the aggregate was calculated from the three components based on the Bruggeman mixing rule (Chýlek et al., 1988). The refractive index of hematite was taken from Sokolik and Toon (1999), and that of quartz was from Krekov (1992); both were listed in Table 1 of Koven and Fung (2006). Feldspar denotes a diverse collection of common aluminium silicate minerals, so its refractive index cannot be determined without further specification. Guided by Nousiainen and Vermeulen (2003) and references cited therein, we adopted a refractive index of $1.545-0.0018 i$ for all bands.
This value provides the best fit to the density-weighted mean spectrum of single scattering albedo of class 2 at Tinga Tingana. Likewise, the size distribution used in the Mie calculation was derived from the density-weighted center of class 2 .

With the above parameters, Mie calculations were carried out for different volume fractions of the three components. Table 4 shows the volume fractions of the components that optimize the calculated single scattering albedo, together with the standard uncertainty in single scattering albedo, when hematite was either included or excluded as a component. The inclusion of hematite in the mixture enables fits with a standard error of below $0.2 \%$ at the arid zone stations, increasing by a factor of $\sim 30$ if hematite is not included. Evidently, hematite absorption provides an adequate explanation of the depression in single scattering albedo at $440 \mathrm{~nm}$ in Australian dust aerosol. The retrieved hematite fraction was found to be relatively insensitive to the assumed refractive index of feldspar, although the ratio of quartz to feldspar is strongly affected. The trend in spatial variation of the volume fraction of hematite is consistent with the soil map of Claquin et al. (1999), which shows higher hematite in the desert regions encompassing Tinga Tingana and Birdsville than in the tropical north. Table 4 suggests a dust hematite content in the range $0.3-0.5 \%$ in the arid zone, but $<0.1 \%$ at the Northern sites.

A similar analysis assuming external mixing requires a much higher hematite content for a given degree of absorption, due to the saturation of absorption where the hematite occurs in large particles. As listed in the right-hand column of Table 4, the hematite fraction by volume ranges between $6 \%$ and $16 \%$ depending on site, with higher values at the arid zone stations.

Koven and Fung (2006) applied this method to infer hematite content in the coarse mode aerosol identified from AERONET stations covering the "dust belt" regions of North Africa, the Middle East and China. Based on the assumption that the hematite is internally mixed, they found hematite volume fractions ranging between $0-0.35 \%$ in summer depending on location, with slightly lower values in winter. The corresponding range assuming external mix- 


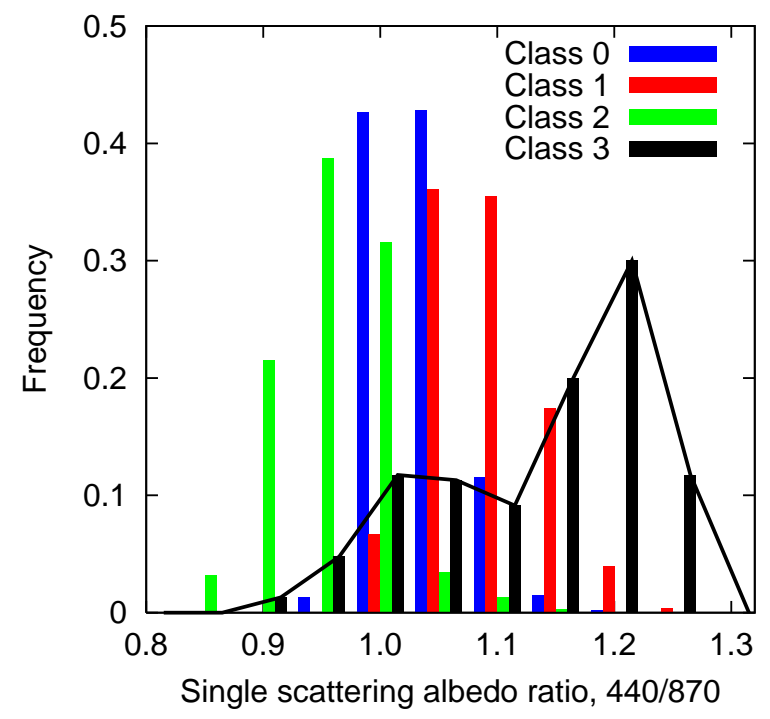

Fig. 6. Frequency distribution of the single scattering albedo ratio $\varpi_{440} / \varpi_{870}$ for the four classes. Class 3 shows a bimodal distribution corresponding to subclasses controlled by the extent of enhanced absorption at $440 \mathrm{~nm}$.

ing was $2.5 \%$ to $14 \%$ in summer, again with somewhat lower values in winter. Hence, the present results suggest that dust over the Australian arid zone is generally richer in hematite than dust over the Northern Hemisphere "dust belt". More detailed analysis of this issue awaits independent and representative measurement of Australian dust mineralogy.

\subsection{Class 3}

Though occurring in only $5 \%$ of the analysed records, class 3 aerosol is of interest in view of its strong absorption, with class-center single scattering albedos from $0.72-0.59$ over the wavelength range $440-1020 \mathrm{~nm}$. The size distribution shown in Fig. 3 is comparable to that of class 0 (aged smoke), with an Ångström coefficient of 1.21.

In view of the egregiously low single scattering albedos of this class, and in order to eliminate the possibility of a spurious result, we scrutinized the AERONET product for any sign of anomaly in the inversion. Instrument miscalibration seems an unlikely cause given that some class 3 episodes recorded at Darwin were observed by a multi-filter rotating shadowband radiometer (MFRSR) operated as part of the Atmospheric Radiation Measurement (ARM) program, in addition to the CSIRO Cimel. During one such episode, on 8 September 2004, aerosol optical depth at $500 \mathrm{~nm}$ from the two systems showed excellent agreement with rms difference of $<0.004$ over a five-hour period. In addition, we performed radiative transfer calculations using the optical properties of individual records for all class 3 retrievals, and for non-class 3 records immediately preceding or following, comparing the simulated and measured radiances. We also collected the sur-

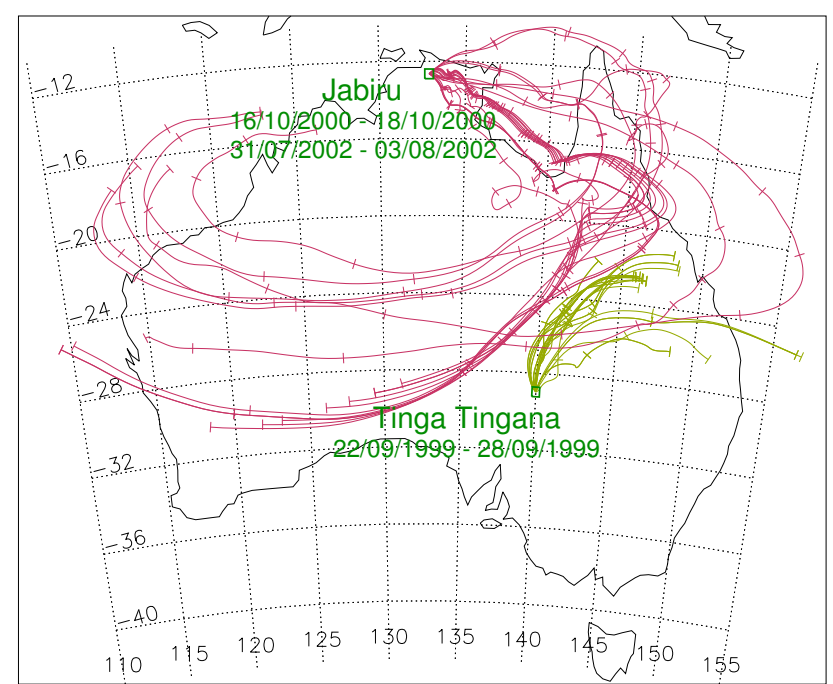

Fig. 7. Airmass back-trajectory analysis for the super-absorptive aerosol with enhanced $440 \mathrm{~nm}$ absorption (class 3a) records observed at Jabiru (initial altitude $1750 \mathrm{~m}$ ) and Tinga Tingana (initial altitude $500 \mathrm{~m}$ ). Two event sequences are shown for Jabiru and one for Tinga Tingana, with the dates indicated in the diagram. The trajectories are marked with ticks every $24 \mathrm{~h}$.

face reflectance data from the MODIS land product, and rainfall records at nearby meteorology stations, seeking indications of significant change of surface reflectance, that could lead to a bias in the inverted single scattering albedo. Based on these exercises, we were unable to identify any abnormality in the class 3 inversions.

Detailed examination of class 3 records reveals that $30 \%$ show a depression in the single scattering albedo at $440 \mathrm{~nm}$ similar to that seen above for the coarse dust class, while the remainder show a monotonic decline in single scattering albedo with increasing wavelength as seen in Fig. 3 at the density-weighted class center. Figure 6 plots the frequency distribution of single scattering albedo ratio $\varpi_{440} / \varpi_{870}$ for all classes. The class 3 histogram appears bimodal either side of $\varpi_{440} / \varpi_{870}=1.1$. For the purposes of the following discussion, this class was subdivided into class $3 \mathrm{a}\left(\varpi_{440} / \varpi_{870}<1\right.$ and class $3 b\left(\varpi_{440} / \varpi_{870}>1\right.$.

Back-trajectory analysis was carried out for all class 3 episodes. Figure 7 shows this analysis for class 3a, comprising observations from Jabiru and Tinga Tingana. All air parcels traversed the Channel Country of Western Queensland, and most crossed the continental coastline, and many traversed the deserts of central and Western Australia. By contrast, a similar analysis of class $3 \mathrm{~b}$ events conveyed no suggestion of preferred source area. 
Since enhanced absorption in the blue spectral region was linked to hematite for coarse dust, we examined its possible role in class $3 \mathrm{a}$ via internal mixtures containing black carbon (BC) and hematite, with feldspar making up the balance. $\mathrm{BC}$ is required to produce the generally low single scattering albedo, and the decline in single scattering albedo with increasing wavelength. Its complex refractive index of was taken from Krekov (1992). An optimal fit to class 3b spectral distribution of single scattering albedo required $\sim 12 \%$ $\mathrm{BC}$ by volume, while class 3 a required $\sim 15 \% \mathrm{BC}$ and $\sim 13 \%$ hematite by volume. This very high hematite content effectively rules out an explanation for class 3 a based on dust, particularly since dust emitted from the Channel Country arises from ablation of iron-poor clay soils leading to "white dust", in contrast to attrition of the iron-rich mantles on quartz grains in the dune fields that gives rise to "red dust" (Bullard and White, 2005).

A more plausible explanation is that class 3 aerosol arises from biomass burning, with unusually soot-rich emissions possibly linked to unique Australian vegetation types and different combustion regimes. Several MODIS images show clear evidence of smoke during class 3 episodes, and on several days class 3 periods occurred in combination with other smoke types. For example, on 8 September 2004 at Darwin, two class 3 inversions were preceded and followed by class 1 events.

Depression of blue-band single scattering albedo in biomass burning aerosol was previously found by Dubovik et al. (1998), who retrieved the optical properties of smoke aerosol over Brazil during the burning seasons of 1993-1995. The depression in $440 \mathrm{~nm}$ single scattering albedo was observed in 1994 and 1995 but not 1993, suggesting the possibility of changes in smoke composition or mixing state. However, while ruling out iron oxide as the source of the absorption, Dubovik et al. (1998) were unable to be more specific about the cause of the enhanced absorption in the blue.

More recently, organic compounds emitted by biomass burning have been found to absorb strongly toward the blue and ultraviolet spectral regions. In particular, Kirchsetter and Novakov (2004) found that the presence of organic carbon increased the spectral dependence of particulate absorption from $\sim \lambda^{-1}$ for sooty urban pollution to $\sim \lambda^{-2}$ for biomass smoke aerosols, while Hoffer et al. (2006) measured strongly increasing absorption from the blue into the ultraviolet spectral region by humic-like substances or HULIS associated with smoke samples collected over the Amazon. Based on these findings, we propose an explanation of class 3 aerosol in terms of soot-rich smoke with different degrees of blueband absorption related to varying amounts of organic material, most likely related to differences in source vegetation and smoke ageing.
Two speculative possibilities for the high BC content implied in this class are as follows. First, sugar cane is grown commercially along much of the Queensland coast, and the class 3 events coincide with cane burning season from July to December. Also, the back trajectories in Fig. 7 suggest a possible association with class $3 \mathrm{a}$ events and the Queensland coast. However, although the deposition from sugar cane burning is known colloquially as "black snow", the burning takes place under moist conditions which would tend to elevate the single scattering albedo through hydration.

A more likely explanation for the class 3 episodes is that they derive from the burning of Spinifex (Triodia sp.), a genus of endemic Australian hummock grasses covering about $20 \%$ of the continent, mostly in the arid zone (DEWR, 2007). Spinifex contains high levels of resin and usually burns with a dense black plume, consistent with high levels of both black and organic carbon implied for this class. The wide distribution of spinifex is consistent with the heterogeneous source area inferred from back-trajectory analysis for class $3 \mathrm{~b}$. On the other hand, under this explanation the apparent connection between class $3 \mathrm{a}$ events and the Queensland coast and Channel Country seen in Fig. 7 is not clear, since spinifex is not prevalent in these areas. However, all of the back trajectories associated with the class 3a episodes recorded at Jabiru also traverse arid regions of the continent, covering much spinifex country. Evidently, further work is required to elucidate the source of this aerosol.

\subsection{Relation to identified aerosol types}

In this section, selected optical properties of the aerosols derived from the foregoing cluster analysis are compared to previously identified aerosol types around the globe. Figure 8 compares the spectral dependence of single scattering albedo of the density-weighted centers of classes 0 (aged smoke) and 1 (fresh smoke) with published data on biomass burning aerosols, most obtained by inversion of AERONET sky-radiance distributions. Class 1 (fresh smoke) closely resembles African savanna smoke as determined by Dubovik et al. (2002) and is clearly aligned with the "absorbing/smoke" class determined by Levy et al. (2007) from global AERONET data (excluding Australia). Class 0 (aged smoke) has similar properties to smoke aerosol from the South American Cerrado, a ground cover type akin to tropical savanna, although it remains more absorbing than a range of other smoke aerosols identified in Fig. 8, and is likewise more absorbing than the "moderately absorbing" global class of Levy et al. (2007). The class 1 result is in good agreement with the value of 0.85 at $530 \mathrm{~nm}$ measured by Gras et al. (1999) for smoke plumes arising from flaming combustion in the Northern Territory. The result from Omar et al. (2005) of 0.80 at $673 \mathrm{~nm}$ appears as an outlier in the present context, a point of note since the models of Omar et al. are used as a basis for the interpretation of data from the spaceborne lidar CALIPSO. 


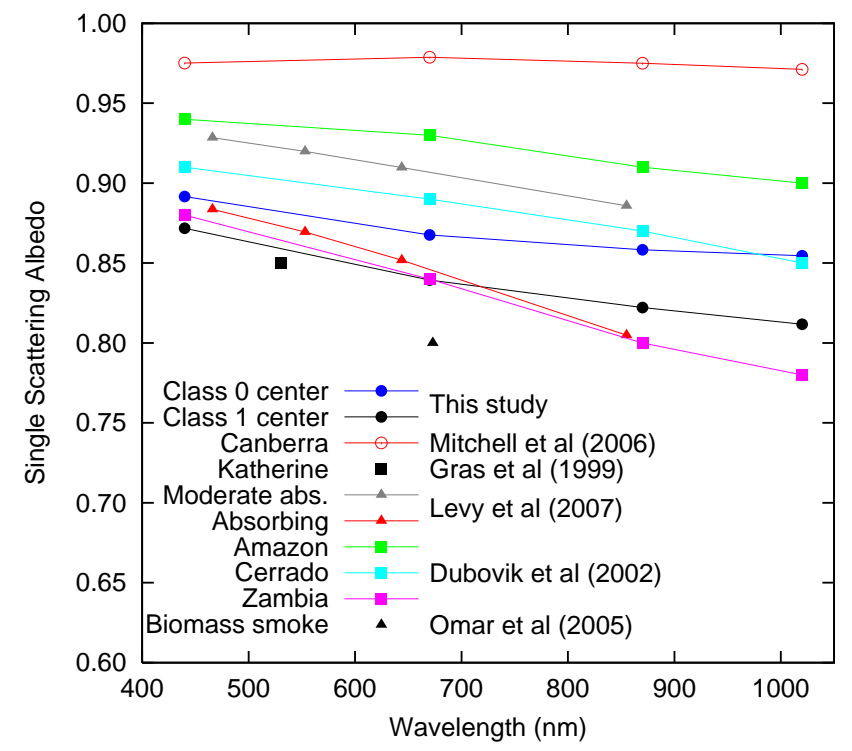

Fig. 8. Comparison of spectral dependence of single scattering albedo of class 0 and 1 centers with results for smoke aerosol reported by other studies.

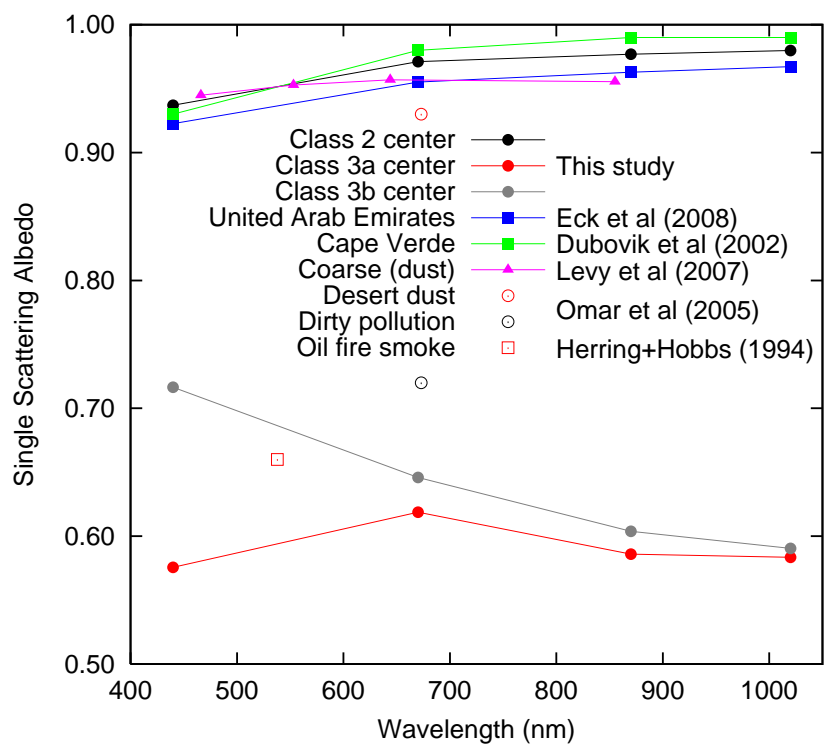

Fig. 9. Comparison of spectral dependence of single scattering albedo of class 2 and 3 with results reported by other studies.

The analogous comparison for dust aerosol is shown in Fig. 9, where single scattering albedo based on the densityweighted center of class 2 (coarse dust) is closely aligned to results from Arabian dust (Eck et al., 2008) and dust off the Sahara at Cape Verde (Dubovik et al., 2002). This result is consistent with the "coarse (dust)" classification of Levy et al (2007), and the "desert dust" classification of Omar et al. (2005).
Table 5. Radiative forcing efficiencies in $\mathrm{W} \mathrm{m}^{-2} \tau_{500}^{-1}$ of the aerosols at the centers of the four identified classes, at top of atmosphere (TOA), surface (SUR) and in the atmosphere (ATM).

\begin{tabular}{crrr}
\hline Class & TOA & SUR & ATM \\
\hline 0 & -29.4 & -135.7 & 106.4 \\
1 & -24.9 & -144.3 & 119.4 \\
2 & -54.9 & -118.5 & 63.6 \\
3 & 31.1 & -239.2 & 270.3 \\
\hline
\end{tabular}

Figure 9 also shows the wavelength dependence of single scattering albedo for class 3 , divided into class $3 \mathrm{a}$ and class $3 b$ on the basis of the ratio $\varpi_{440} / \varpi_{870}$ as discussed in Sect. 4.3 above. A comparably low single scattering albedo of 0.66 at $538 \mathrm{~nm}$ was found by Herring and Hobbs (1994) for the plume arising from the Kuwait oil fires following the 1991 Gulf War. In addition, Omar et al. (2005) identified a cluster labelled "dirty pollution" with a single scattering albedo of 0.72 at $673 \mathrm{~nm}$. However, neither case bears any comparison with the present class 3 result in terms of the source of the aerosol.

\subsection{Aerosol radiative forcing}

The radiative impact of different aerosol types can be usefully compared by calculation of their radiative forcing efficiency, defined as aerosol radiative forcing per unit optical depth. These were calculated for optical properties based on the centers of the four classes, using radiative transfer calculations carried out using the DISORT-based Coupled OceanAtmosphere Radiative Transfer (COART) model (Jin et al., 2006). Profiles of aerosol and water vapour were selected from available model options, which are based on the widely used profiles originally developed for the MODTRAN radiative transfer code (Berk et al., 2000). In particular, the aerosol vertical distribution was assumed to follow the "rural" profile in the mixed layer, and the "background" profile in the stratosphere. The column water vapour loading was set to $4.2 \mathrm{~g} \mathrm{~cm}^{-2}$, typical of the dry season conditions over the tropical stations where the majority of the biomass burning episodes were recorded. A lower value would be more typical of the arid zone stations. The surface was assumed to reflect isotropically with albedo rising from 0.1 at $440 \mathrm{~nm}$ to 0.25 at $1020 \mathrm{~nm}$. Integration over the solar spectrum was obtained by dividing the spectral range $0.25-4.0 \mu \mathrm{m}$ into 138 bands. To capture the diurnal variation in sun angle, the calculations were carried over a day in mid January at coordinates of latitude $30^{\circ} \mathrm{S}$, longitude $135^{\circ} \mathrm{E}$ corresponding to central Australia. Calculations were made from sunrise to sunset at $1.5 \mathrm{~h}$ intervals, then the daily mean radiative forcing calculated as

$$
\Delta F=\frac{1}{T} \int_{0}^{T} \Delta F(t) d t
$$


where $\Delta F=F_{\text {net }}$ (aerosol) $-\mathrm{F}_{\text {net }}$ (clear sky) represents the change in flux caused by the addition of the aerosol, with negative values denoting cooling, and $T$ is the time between sunrise and sunset. Table 5 shows radiative forcing efficiencies for the four class centers calculated at the top of atmosphere (TOA), surface (SUR) and their difference corresponding to energy deposited in the atmosphere (ATM).

The forcing efficiencies for the biomass burning aerosol classes 0 and 1 accord with those found in other parts of the globe; for example, Satheesh and Ramanathan (2000) found TOA values of $-25 \mathrm{~W} \mathrm{~m}^{-2} \tau_{500}^{-1}$ over the Indian Ocean while Bergstrom et al. (2003) found values of -14 and $-43 \mathrm{~W} \mathrm{~m}^{-2} \tau_{500}^{-1}$ for different African smoke plumes during the SAFARI experiment. The results for classes 2 and 3 demonstrate the impact of SSA on radiative forcing, with TOA results of opposite sign for the two classes. Despite the hematite absorption, the coarse dust exerts the largest planetary cooling of any class and the lowest atmospheric heating. In contrast, class 3 exerts positive forcing of $31.1 \mathrm{~W} \mathrm{~m}^{-2} \tau_{500}^{-1}$ at TOA and very large energy deposition in the atmosphere at $270.3 \mathrm{~W} \mathrm{~m}^{-2} \tau_{500}^{-1}$. This implies that even at background levels of $\tau_{500} \sim 0.03$, this aerosol would exert a forcing of $\sim+1 \mathrm{~W} \mathrm{~m}^{-2}$ at TOA with $\sim 8 \mathrm{~W} \mathrm{~m}^{-2}$ deposited in the atmospheric column, with expected consequences for regional atmospheric dynamics.

\section{Conclusions}

Cluster analysis of column-integrated aerosol optical properties over the Australian continent obtained during episodes of enhanced aerosol loading suggests the existence of four distinct classes. Application of back-trajectory analysis and examination of the optical properties enables identification of the first three classes as aged biomass burning smoke, fresh smoke, and coarse dust respectively. The optical properties of these aerosol classes are congruent with previous analyses of similar worldwide aerosol types, and available in situ measurements. The fourth class is a fine, super-absorptive aerosol that shows a variable degree of absorption in the blue spectral band. The source of this aerosol is uncertain, but the generally low single scattering albedo suggests a smoke aerosol with a high black carbon content, while the variable blue-band absorption may be related to organic compounds such as the humic-like substances (HULIS) emitted during the burning of certain vegetation types. The widespread hummock grasses known as Spinifex (Triodia sp.) are endemic to Australia and represent a possible source.

Radiative transfer calculations for the smoke classes indicate similar aerosol radiative forcing efficiencies to biomass burning aerosol from other savanna regions around the globe, with values of between -25 to $-30 \mathrm{~W} \mathrm{~m}^{-2} \tau_{500}^{-1}$ at the top of atmosphere, and atmospheric heating of 110 $120 \mathrm{~W} \mathrm{~m}^{-2} \tau_{500}^{-1}$. The coarse dust aerosol at the Central Australian stations appears to contain somewhat higher levels of hematite than results reported for Northern Hemisphere deserts. This aerosol produces a strongly negative radiative forcing at the top of atmosphere of $\sim-55 \mathrm{~W} \mathrm{~m}^{-2} \tau_{500}^{-1}$. By contrast, the super-absorptive aerosol produces a positive forcing of $\sim 31 \mathrm{~W} \mathrm{~m}^{-2} \tau_{500}^{-1}$ at the top of atmosphere with very large deposition of energy in the aerosol layer $\left(\sim 270 \mathrm{~W} \mathrm{~m}^{-2} \tau_{500}^{-1}\right)$, suggesting significant dynamical effects even at non-episodic levels.

Further work is required to determine the sources and distribution of these aerosols. In particular, the network used in the present study was sparse, and hence class incidence frequencies are likely to be biased by a combination of the timing and distribution of the source events, and subsequent transport. In addition, the present analysis includes only episodes of strongly enhanced aerosol loading, so it is important to establish the relationship between these and the aerosol distribution under quiescent conditions. The present results can be used to guide the location and timing of campaign-based in situ measurements.

Finally, satellite aerosol retrievals are needed to provide regional and continental coverage, but require a priori knowledge of the optical properties of likely aerosol types. The results reported here will be used to better adapt candidate inversion algorithms for sensors such as AATSR and MISR for use over the Australian continent. Continental-scale aerosol distributions will be used to inform climate simulations via GCMs with treatment of interactive aerosol. In particular, Rotstayn et al. (2009b) demonstrated a marked improvement in GCM simulations of Australian rainfall variability when interactive aerosol was included, with a suggested feedback between increased dust levels and reduced rainfall. This is an area in sharp focus at present given ongoing drought conditions in South-Eastern Australia since 2002.

\section{Appendix A}

To facilitate wider application of these results, this section presents the optical properties at the four class centers in a form suitable for Mie theory calculations. Table A1 lists the complex refractive indices $m=n-i k$ for each class center at the four inversion wavelengths. The size distributions shown in Fig. 3 were fitted as the sum of multi-modal log-normal functions with each mode defined by

$$
\frac{d V}{d \ln r}=\frac{V}{\sqrt{2 \pi} \ln \sigma_{g}} \exp \left[-\frac{\left(\ln r-\ln \bar{r}_{v}\right)^{2}}{2 \ln ^{2} \sigma_{g}}\right]
$$

where $V$ is the column-integrated particle volume, $\bar{r}_{v}$ is the volume median radius, and $\sigma_{g}$ is the geometric standard deviation. Unweighted fits to the coarse mode of the inverted size distribution in each class were poor due to the rapid decline in the large particle tail with increasing size. This may reflect a systematic underestimate due to the limited information content of the inversion, which attempts to infer par- 
Table A1. Refractive indices of the four aerosol types at the density-weighted center of each class. The coefficient of variation for the real part was in the range $0.07 \%$ to $0.15 \%$, whilst for the imaginary part it was $\sim 1 \%$ for classes 0,1 and 3 , and $\sim 5 \%$ for class 2 (dust).

\begin{tabular}{rcccccccc}
\hline & \multicolumn{2}{c}{ Class 0 } & \multicolumn{2}{c}{ Class 1 } & \multicolumn{2}{c}{ Class 2 } & \multicolumn{2}{c}{ Class 3 } \\
$\lambda(\mathrm{nm})$ & $n$ & $k\left(10^{-3}\right)$ & $n$ & $k\left(10^{-3}\right)$ & $n$ & $k\left(10^{-3}\right)$ & $n$ & $k\left(10^{-3}\right)$ \\
\hline 440 & 1.50 & 13.9 & 1.50 & 20.2 & 1.58 & 1.95 & 1.59 & 71.1 \\
670 & 1.52 & 13.6 & 1.52 & 19.9 & 1.58 & 0.98 & 1.59 & 80.2 \\
870 & 1.53 & 13.2 & 1.53 & 18.8 & 1.57 & 0.96 & 1.59 & 84.6 \\
1020 & 1.53 & 13.2 & 1.54 & 18.8 & 1.57 & 0.96 & 1.59 & 83.7 \\
\hline
\end{tabular}

Table A2. Parameters of multi-modal log-normal volume size distributions for the four aerosol types at the density-weighted center of each class. $V$ is the column-integrated particle volume $\left(\mu \mathrm{m}^{3} / \mu \mathrm{m}^{2}\right), \bar{r}_{v}$ is the volume median radius $(\mu \mathrm{m})$, and $\sigma_{g}$ is the geometric mean standard deviation $(\mu \mathrm{m})$.

\begin{tabular}{lccccc}
\hline & Mode & Class 0 & Class 1 & Class 2 & Class 3 \\
\hline$V$ & Fine & 0.104 & 0.111 & 0.016 & 0.075 \\
$\bar{r}_{v}$ & & 0.130 & 0.128 & 0.109 & 0.133 \\
$\sigma_{g}$ & & 1.404 & 1.390 & 1.466 & 1.488 \\
\hline$V$ & Medium & & & 0.431 & \\
$\bar{r}_{v}$ & & & & 1.737 & \\
$\sigma_{g}$ & & & & 2.072 & \\
\hline$V$ & Coarse & 0.236 & 0.185 & 0.547 & 0.232 \\
$\bar{r}_{v}$ & & 3.638 & 5.122 & 4.815 & 4.431 \\
$\sigma_{g}$ & & 3.032 & 4.287 & 1.512 & 3.274 \\
\hline
\end{tabular}

ticle size distribution up to $15 \mu \mathrm{m}$ in radius when the longest wavelength used in the inversion is only $1.02 \mu \mathrm{m}$. Weinzierl et al. (2009) presented evidence that AERONET inversions significantly underestimate the volume median diameter of coarse mode dust aerosol, although this issue is controversial (Reid et al., 2003). In the present case, satisfactory fits were obtained by progressively de-weighting the large particle tail of the coarse mode of the inversion, with a function decreasing linearly from 1 to 0 over the size range 1.0 to $15 \mu \mathrm{m}$. Bimodal fits were adequate for the smoke classes 0,1 and 3, while a trimodal distribution was necessary for class 2 (dust). Resulting parameters of the size distributions are given in Table A2.

Acknowledgements. The authors wish to thank site managers including the staff at the Darwin Atmospheric Radiation Measurement program site, staff of the Environmental Research Institute of the Supervising Scientist (ERISS) at Jabiru, M. Byers (deceased) at Lake Argyle, and members of the Queensland police force for support at Birdsville. D. Graetz and S. Campbell provided valued field work support during this project. This work was supported in part by funding through the Australian Department of Climate Change through the Australian Climate Change Science Program, and also by the Office of Biological and Environmental Research of the US Department of Energy under contract 23662-001-01 3T as part of the Atmospheric Radiation Measurement program.

Edited by: G. Feingold

\section{References}

Abel, S. J., Haywood, J. M., Highwood, E. J., Li, J., and Buseck, P. R.: Evolution of biomass burning aerosol properties from an agricultural fire in southern Africa, Geophys. Res. Lett., 30(15), 1783, doi:10.1029/2004GL017342, 2003.

Armstrong, D.: Natural History of the North East Deserts, ISBN 0 95966275 8, Royal Society of South Australia Inc., 1990.

Bergstrom, R. W., Pilewskie, P., Schmid, B., and Russell, P. B.: Estimates of the spectral aerosol single scattering albedo and aerosol radiative effects during SAFARI 2000, J. Geophys. Res., 108(D13), 8474, doi:10.1029/2002JD002435, 2003.

Berk, A., Anderson, G. P., Acharya, P. K., Chetwynd, J. H., Bernstein, L. S., Shettle, E. P., Matthews, M. W., and Adler-Gordon, S. M.: MODTRAN4 User's Manual, Tech. rep., Air Force Research Laboratory, Hanscom AFB, MA, USA, 2000.

Bicici, E. and Yuret, D.: Locally Scaled Density Based Clustering, Lect. Notes Comput. Sc., 4431, 739-748, 2007.

Bullard, J. E. and White, K.: Dust production and the release of iron oxides resulting from the aeolian abrasion of natural dune sands, Earth Surf. Proc. Land., 30, 95-106, 2005.

Carr, S. B., Gras, J. L., Hackett, M. T., and Keywood, M. D.: Aerosol Characterisation in the Northern Territory of Australia during the Dry Season with an Emphasis on Biomass Burning, Tech. rep., Intelligence, Surveillance and Reconnaissance Division Information Sciences Laboratory, Defence Science and Technology Organisation, Australia, DSTO-RR-0298, 2005.

Cassar, N., Bender, M. L., Barnett, B. A., Fan, S., Moxim, W. J., Levy II, H., and Tilbrook, B.: The Southern Ocean biological response to aeolian iron deposition, Science, 317, 1067-1070, 2007.

Chýlek, P., Srivastava, V., Pinnick, R. G., and Wang, R. T.: Scattering of electromagnetic waves by composite spherical particles: experiments and effective medium approximations, Appl. Optics, 27, 2396-2404, 1988.

Claquin, T., Schulz, M., and Balkanski, Y. J.: Modeling the mineralogy of atmospheric dust sources, J. Geophys. Res., 104, 2224322256, 1999.

DEWR: Australia's Native Vegetation: A summary of Australia's Major Vegatation Groups, Tech. rep., Department of the Environment and Water Resources, Australian Government, Canberra, ACT, 42 pp., 2007.

Draxler, R. R. and Hess, G. D.: Description of the HYSPLIT_4 modeling system, Tech. rep., NOAA, Silver Spring, Md., NOAA Tech. Memo. ERL ARL-224, 24 pp., 1997.

Dubovik, O. and King, M. D.: A flexible inversion algorithm for retrieval of aerosol optical properties from Sun and sky radiance measurements, J. Geophys. Res., 105, 20673-20696, 
doi:10.1029/2000JD900282, 2000.

Dubovik, O., Holben, B. N., Kaufman, Y. J., Yamasoe, M., Smirnov, A., Tanré, D., and Slutsker, I.: Single-scattering albedo of smoke retrieved from the sky radiance and solar transmittance measured from ground, J. Geophys. Res., 103, 31903-31923, 1998.

Dubovik, O., Smirnov, A., Holben, B. N., King, M. D., Kaufman, Y. J., Eck, T. F., and Slutsker, I.: Accuracy assessments of aerosol optical properties retrieved from Aerosol Robotic Network (AERONET) Sun and sky radiance measurements, J. Geophys. Res., 105, 9791-9806, doi:10.1029/2000JD900040, 2000.

Dubovik, O., Holben, B., Eck, T. F., Smirnov, A., Kaufman, Y. J., King, M. D., Tanré, D., and Slutsker, I.: Variability of absorption and optical properties of key aerosol types observed in worldwide locations, J. Atmos. Sci., 59, 590-608, 2002.

Dubovik, O., Sinyuk, A., Lapyonok, T., Holben, B. N., Mishchenko, M., Yang, P., Eck, T. F., Volten, H., Munoz, O., Veihelmann, B., van der Zande, W. J., Leon, J.-F., Sorokin, M., and Slutsker, I.: Application of spheroid models to account for aerosol particle nonsphericity in remonte sensing of desert dust, J. Geophys. Res., 111(D11), D11208, doi:10.1029/2005JD006619, 2006.

Eck, T. F., Holben, B. N., Ward, D. E., Mukelabai, M. M., Dubovik, O., Smirnov, A., Schafer, J. S., Hsu, N. C., Piketh, S. J., Queface, A., Le Roux, J., Swap, R. J., and Slutsker, I.: Variability of biomass burning aerosol optical characteristics in southern Africa during the SAFARI 2000 dry season campaign and a comparison of single scattering albedo estimates from radiometric measurements, J. Geophys. Res., 108(D13), 8477, doi:10.1029/2002JD002321, 2003.

Eck, T. F., Holben, B. N., Reid, J. S., Sinyuk, A., Dubovik, O., Smirnov, A., Giles, D., O’Neill, N. T., Tsay, S.-C., Ji, Q., Mandoos, A. A., Khan, M. R., Reid, E. A., Schafer, J. S., Sorokine, M., Newcomb, W., and Slutsker, I.: Spatial and temporal variability of column-integrated aerosol optical properties in the southern Arabian Gulf and United Arab Emirates in summer, J. Geophys. Res., 113, D01204, doi:10.1029/2007JD008944, 2008.

Evans, L. F., King, N. K., MacArthur, D. A., Packham, D. R., and Stephens, E. T.: Further studies of the nature of bushfire smoke, Technical Paper 2, Division of Applied Organic Chemistry, CSIRO, 12 pp., 1976.

Forster, P., Ramaswamy, V., Artaxo, P., Berntsen, T., Betts, R., Fahey, D., Haywood, J., Lean, J., Lowe, D., Myhre, G., Nganga, J., Prinn, R., Raga, G., Schulz, M., and Dorland, R. V.: Changes in Atmospheric Constituents and in Radiative Forcing, in: Climate Change 2007: The Physical Science Basis, Contribution of Working Group I to the Fourth Assessment Report of the Intergovernmental Panel on Climate Change, Cambridge University Press, Cambridge, United Kingdom and New York, NY, USA, edited by: Solomon, S., Qin, D., Manning, M., Chen, Z., Marquis, M., Averyt, K. B., Tignor, M., and Miller, H. L., 2007.

Gras, J. L., Jensen, J. B., Okada, K., Ikegami, M., Zaizen, Y., and Makino, Y.: Some optical properties of smoke aerosol in Indonesia and tropical Australia, Geophys. Res. Lett., 26, 1393-1396, 1999.

Grira, N., Crucianu, M., and Boujemaa, N.: Unsupervised and semi-supervised clustering: a brief survey, in A Review of Machine Learning Techniques for Processing Multimedia Content, Report of the MUSCLE European Network of Excellence (6th Framework Program), 12 pp., 2005.
Herring, J. A. and Hobbs, P. V.: Radiatively Driven Dynamics of the Plume from 1991 Kuwait Oil Fires, J. Geophys. Res., 99, 18809-18826, 1994.

Hoffer, A., Gelencsér, A., Guyon, P., Kiss, G., Schmid, O., Frank, G. P., Artaxo, P., and Andreae, M. O.: Optical properties of humic-like substances (HULIS) in biomass-burning aerosols, Atmos. Chem. Phys., 6, 3563-3570, 2006,

http://www.atmos-chem-phys.net/6/3563/2006/.

Holben, B. N., Eck, T. F., Slutsker, I., Tanré, D., Buis, J. P., Setzer, A., Vermote, E., Reagan, J. A., Kaufman, Y. J., Nakajima, T., Lavenu, F., Jankowiak, I., and Smirnov, A.: AERONET - A federated instrument network and data archive for aerosol characterization, Remote Sens. Environ., 66, 1-16, 1998.

Kinne, S., Schulz, M., Textor, C., Guibert, S., Balkanski, Y., Bauer, S. E., Berntsen, T., Berglen, T. F., Boucher, O., Chin, M., Collins, W., Dentener, F., Diehl, T., Easter, R., Feichter, J., Fillmore, D., Ghan, S., Ginoux, P., Gong, S., Grini, A., Hendricks, J., Herzog, M., Horowitz, L., Isaksen, I., Iversen, T., Kirkevåg, A., Kloster, S., Koch, D., Kristjansson, J. E., Krol, M., Lauer, A., Lamarque, J. F., Lesins, G., Liu, X., Lohmann, U., Montanaro, V., Myhre, G., Penner, J., Pitari, G., Reddy, S., Seland, O., Stier, P., Takemura, T., and Tie, X.: An AeroCom initial assessment - optical properties in aerosol component modules of global models, Atmos. Chem. Phys., 6, 1815-1834, 2006,

http://www.atmos-chem-phys.net/6/1815/2006/.

Kirchsetter, T. W. and Novakov, T.: Evidence that the spectral dependence of light absorption by aerosols in affected by organic carbon, J. Geophys. Res., 109, D21208, doi:10.1029/2004JD004999, 2004.

Kotsiantis, S. B. and Pintelas, P. E.: Recent advances in clustering: A brief survey, WSEAS Trans. Info. Sci., 1, 73-81, 2004.

Koven, C. D. and Fung, I.: Inferring dust composition from wavelength-dependent absorption in Aerosol Robotic Network (AERONET) data, J. Geophys. Res., 111, D14205, doi:10.1029/2005JD006678, 2006.

Krekov, G. M.: Models of Atmospheric Aerosols, in Aerosol Effects on Climate, edited by: Jennings, S. G., 9-72, Univ. of Ariz. Press, Tucson, 1992.

Levy, R. C., Remer, L. A., and Dubovik, O.: Global aerosol optical properties and application to Moderate Resolution Imaging Spectroradiometer aerosol retrieval over land, J. Geophys. Res., 112, D13210, doi:10.1029/2006JD007815, 2007.

Luhar, A. K., Mitchell, R. M., Meyer, C. P. M., Qin, Y., Campbell, S. K., Gras, J. L., and Parry, D.: Biomass burning emissions over northern Australia constrained by aerosol measurements: II - model validation, and impacts on air quality and radiative forcing, Atmos. Environ., 42, 1647-1664, 2008

McTainsh, G. H., Lynch, A. W., and Trews, E. K.: Climate controls upon dust storm occurrence in eastern Australia, J. Arid Emviron., 39, 457-466, 1998.

Meyer, C. P. M., Luhar, A. K., and Mitchell, R. M.: Biomass burning emissions over northern Australia constrained by aerosol measurements: I - modelling the distribution of hourly emissions, Atmos. Environ., 42, 1629-1646, 2008.

Mitchell, R. M. and Campbell, S.: The Australian Aerosol Ground Station Network: Status Report and Development of a Radiometric Calibration Facility, Opt. Pur y Apl., 3259-3262, 2004.

Mitchell, R. M. and Forgan, B. W.: Aerosol measurements in the Australian Outback: intercomparison of sun photometers, J. At- 
mos. Ocean. Tech., 20, 54-66, doi:10.1175/1520-0426(2003), 2003.

Mitchell, R. M., O’Brien, D. M., and Campbell, S. K.: Characteristics and radiative impact of the aerosol generated by the Canberra firestorm of January 2003, J. Geophys. Res., 111(D2), D02204, doi:10.1029/2005JD006304, 2006.

Nousiainen, T. and Vermeulen, K.: Comparison of measured singlescattering matrix of feldspar particles with T-matrix simulations using spheroids, J. Quant. Spectrosc. Ra., 79-80, 1031-1042, 2003.

O'Brien, D. M. and Mitchell, R. M.: Atmospheric heating due to carbonaceous aerosol in northern Australia - confidence limits based on TOMS aerosol index and sun-photometer data, Atmos. Res., 66, 21-41, doi:10.1016/S0169-8095(02)00173-4, 2003.

Omar, A. H., Won, J.-G., Winker, D. M., Yoon, S.-C., Dubovik, O., and McCormick, M. P.: Development of global aerosol models using cluster analysis of Aerosol Robotic Network (AERONET) measurements, J. Geophys. Res., 110, D10S14, doi:10.1029/2004JD004874, 2005.

Reid, J. S., Jonsson, H. H., Maring, H. B., Smirnov, A., Savoie, D. L., Cliff, S. S., Reid, E. A., Livingstone, J. M., Meier, M. M., Dubovik, O., and Tsay, S.-C.: Comparison of size and morphological measurements of coarse mode dust particles from Africa, J. Geophys. Res., 108(D19), 8593, doi:10.1029/2002JD002485, 2003.

Rotstayn, L. D., Forgan, B. W., Gabric, A. J., Gallbally, I. E., Gras, J. L., Keywood, M. D., Luhar, A. K., Mitchell, R. M., and Young, S. A.: Possible impacts of anthropogenic and natural aerosols on Australian climate and weather: a review, Int. J. Climatol., 29, 461-479, doi:10.1002/joc.1729, www.interscience. wiley.com, 2009a.
Rotstayn, L. D., Collier, M., Hendon, H. H., Smith, I. N., and Syktus, J.: Improved simulation of Australian ENSO-related rainfall variability in a GCM with an interactive aerosol treatment, Int. J. Climatol., submitted, 2009b.

Sander, J., Ester, M., Kriegel, H., and Xu, X.: Density-Based Clustering in Spatial Databases: The Algorithm GDBSCAN and its Applications, Data Min. Knowl. Disc., 2, 169-194, 1998.

Satheesh, S. K. and Ramanathan, V.: Large differences in tropical aerosol forcing at the top of the atmosphere and Earth's surface, Nature, 405, 60-63, doi:10.1038/35011039, 2000.

Sokolik, N. and Toon, O. B.: Incorporation of mineralogical composition into models of the radiative properties of mineral aerosol from UV to IR wavelengths, J. Geophys. Res., 104, 9423-9444, 1999.

Tanaka, T. Y. and Chiba, M.: A numerical study of the contributions of dust source regions to the global dust budget, Global Planet. Change, 52, 88-104, 2006.

Vines, R. G., Gibson, L., Hatch, A. B., King, N. K., MacArthur, D. A., Packham, D. R., and Taylor, R. J.: On the nature, properties and behaviour of bushfire smoke, Technical Paper 1, Division of Applied Chemistry, CSIRO, 75-80, 1971.

Webb, N. P., McGowan, H. A., Phinn, S. R., and McTainsh, G. H.: AUSLEM (AUStralian Land Erodibility Model): A tool for identifying wind erosion hazard in Australia, Geomorphology, 78, 179-200, 2006.

Weinzierl, M., Petzold, A., Esselborn, M., Wirth, M., Rasp, K., Kandler, K., Shütz, L., Koepke, P., and Fiebig, M.: Airborne measurements of dust layer properties, particle size distribution and mixing state of Saharan dust during SAMUM 2006, Tellus, 61B, 96-117, doi:10.111/j.1600-0889.2008.00392.x, 2009. 